\title{
Advances in the generation of transgenic pigs via embryo-derived and primordial germ cell-derived cells
}

\author{
J. A. Piedrahita ${ }^{* 1,2,3}$, K. Moore ${ }^{1,3}$, C. Lee ${ }^{2,3}$, B. Oetama ${ }^{1,3}$, \\ R. Weaks ${ }^{1,3}$, J. Ramsoondar ${ }^{1,3}$, J. Thomson ${ }^{1,3}$ and J. Vasquez ${ }^{2,3}$ \\ ${ }^{1}$ Department of Veterinary Anatomy and Public Health, ${ }^{2}$ Department of Animal Sciences, and \\ ${ }^{3}$ Center for Animal Biotechnology, Texas A\&M University, College Station, TX 77843-4458, USA
}

The development of new technologies that would increase the efficiency for generation of transgenic livestock and would overcome some of the problems associated with random insertion of the transgene will greatly benefit animal agriculture. A potential alternative technology to pronuclear injection for the generation of transgenic pigs involves the isolation, culture and genetic manipulation of cell lines that can be reintroduced into the embryo for participation in the formation of the germ cells. We have isolated and cultured pig primordial germ cells (PGC) while maintaining them in an undifferentiated state as determined by morphology and alkaline phosphatase (AP) activity. More importantly, PGC-derived cells were stably transformed with the green fluorescent protein.marker driven by the cytomegalovirus promoter. After visual identification of transgenic colonies, the pluripotential characteristics of the transgenic PGC-derived cells were tested by chimaera formation and to date we have identified, by genomic Southern blots, two chimaeric fetuses that contain tissues with the transgene incorporated into their chromosomes. To our knowledge, this is the first report of a chimaeric transgenic pig fetus obtained via a cultured cell line.

\section{Methods for the Genetic Modification of Pigs}

\section{Introduction}

Genome modification of selected domestic species has been the focus of intense research effort for the past 15 years. At present, the only techniques available for the generation of transgenic domestic animals are pronuclear injection or viral vectors. Production of transgenic pigs by pronuclear injection has demonstrated the difficulty and inefficiency of the procedure (Wall, 1996). This is due in part to the nature of the pronuclear injection technique itself, which leads to the random integration of the introduced DNA with unpredictable and, in some cases, undesirable results (Pursel et al., 1989), and due in part to the high cost associated with the generation of transgenic pigs. Although viral transformation tends to be more efficient than pronuclear injection, it is also accompanied by problems associated with random insertion, mosaicism due to multiple integrations, and technical difficulties associated with the generation of replication defective recombinant viral vectors. Thus, in domestic animals, the lack of complete information on the regulatory sequences required for proper expression and regulation of the transgene are compounded by the technical disadvantages associated with the generation of transgenic animals.

Some of the drawbacks of pronuclear injection and viral vectors can be overcome by the use of a technique known as homologous recombination (Koller and Smithies, 1992). This technique allows the precise modification of existing genes, overcomes the problems of positional effects and insertional inactivation, and allows the inactivation of specific genes (Piedrahita $e t$ al., 1992) as well 
as the replacement of one gene for another. Unfortunately the efficiency of the procedure is so low that it cannot be used directly on embryos, but must make use of a carrier cell line. The cell line used to date is the embryonic stem (ES) cell as it allows easy manipulation and selection in vitro followed by the generation, by ES-blastocyst injection, of a transgenic animal carrying those changes. Unfortunately, homologous recombination can be performed only in mice, as it has not been possible to isolate domestic animal ES cells that permit the same genetic manipulations. Therefore, a system is required that allows the culture and genetic manipulation of domestic animal cell lines with ESlike qualities.

\section{Embryonic stem (ES) cells and primordial germ cell-derived (EG) cells}

Embryonic stem cells isolated from the inner cell mass (ICM) of the preimplantation embryo can proliferate indefinitely in an undifferentiated state, are capable of differentiating in vitro and in vivo, and can contribute to the formation of normal tissues and organs of a chimaeric individual when injected into a host embryo. Embryonic stem cells can differentiate into several tissue types (Doetschman et al., 1985; Koller and Smithies, 1992) and their differentiation can be stimulated in vitro by modifying culture conditions, and in vivo by injection of ES cells into athymic mice (Doetschman et al., 1985). When allowed to differentiate in vitro, ES cells form structures known as embryoid bodies, which closely resemble the embryo-proper portion of the mouse embryo at day 5 (Doetschman et al., 1985).

The ability to colonize the germ line following culture and genetic manipulation has made ES cells a powerful tool for the modification of the genome in mice. Chimaeras produced between genetically modified ES cells and normal embryos have been used to study gene regulation in vivo (Stewart et al., 1985) as well as germ-line transmission of introduced genes (Smithies, 1991). In addition, ES cells have been used to study targeted modification of genes by homologous recombination (Smithies, 1991). Although most of the research on ES cells has been done in mice, attempts at developing the ES technology in other mammalian species have been reported by several investigators (see Stice and Strelchenko, 1995 for review). Doetschman et al. (1988) showed that ES cells can be isolated from hamster embryos using feeders composed of murine primary embryonic fibroblasts. Several investigators, using STO (a transformed mouse embryonic fibroblast cell line) as feeder layers, have reported the isolation of pig embryo-derived cell lines with ES-like morphology and a limited ability to differentiate in vitro and in vivo (Evans et al., 1990; Notarianni et al., 1990; Piedrahita et al., 1990; Gerfen and Wheeler, 1995). In pigs, not only has it been demonstrated that injection of ICM into the blastocoel of a developing blastocyst results in chimaeric pigs (Anderson et al., 1994; Onishi et al., 1994) but, in addition, there have been reports of the ability of cultured ICM-derived ES-like cells to contribute to the generation of a chimaeric pig (Wheeler, 1994). However, not only was the degree of reported chimaerism low, but also there has been no report of germ-line transmission of the ES genotype (Wheeler, 1994; Gerfen and Wheeler, 1995). Without germ-line transmission, any genetic changes that have been introduced into the ES cell cannot be passed on to the next generation and as a result the animals have little, if any, practical value.

Recently, it has been reported that mouse cell lines derived from primordial germ cells behave in a similar way to ES cells and are capable of contributing to the germ line (Labosky et al., 1994). These cells, referred to as EG cells or PGC-derived cells (Labosky et al., 1994; Strelchenko, 1996), are similar to ES cells in terms of markers of the undifferentiated state, as well as their ability to colonize the germ line following injection into a host blastocyst (Labosky et al., 1994; Stewart et al., 1994). Thus, even though the starting tissue source or cellular phenotype differs from the ICM-derived cell lines, once established they have similar properties. Shim $e$ al. (in press) have reported the ability of PGCderived cell lines to contribute to the formation of a pig chimaera, demonstrating the pluripotential characteristics of these cell lines. We have extended this observation by demonstrating the ability of genetically transformed PGCs to contribute to chimaera formation, indicating that the cells we have isolated have pluripotential characteristics, and that the genetic transformation and selection procedure do not interfere with the ability of the cells to participate in chimaera formation. 


\section{Progress Towards Isolation and Characterization of Pig Embryonic Stem Cells}

Our initial experiments in this area were concentrated on identifying homologous or heterologous cytokines that could maintain ICM-derived cells in an undifferentiated state. Several parallel approaches were used. First, we developed a simple in vitro assay capable of detecting the effects of added cytokines on the differentiation of pig ICM (Moore and Piedrahita, 1996; 1997). Second, we isolated and characterized several pig cytokines that may assist in the isolation of pluripotential pig embryo-derived cell lines. Third, we examined the potential use of PGCs for the development of pluripotential or totipotential cell lines.

\section{Development and validation of an in vitro differentiation assay}

An exogenous supply of haematopoietic cytokines is essential for maintaining mouse embryonic stem (ES) cells in a proliferative yet undifferentiated state. Ip et al. (1992) and Stahl et al. (1993) demonstrated that haematopoietic cytokines use the gp130 signal transduction pathway to maintain this phenotype, yet their involvement towards maintaining pig ES cell pluripotency has not been established. Isolation and maintenance of pig ES cells have been hindered by the inability to inhibit differentiation of the pig inner cell mass (pICM) in vitro. Optimizing culture conditions for the pICM is essential. Therefore, the objective of these studies was to determine the effectiveness of several heterologous haematopoietic cytokines and culture medium at maintaining the isolated pig ICM in an undifferentiated state.

We have developed a grading system to detect changes in the differentiation status of in vitro cultured pICM (Moore and Piedrahita, 1996, 1997). In the first experiment pig ICMs (day 7) were isolated by immunosurgery and cultured for 4 days in DMEM-based medium (D medium) or DMEM/Hams F-10 (1:1)-based medium (D/H medium) with or without human leukaemia inhibitory factor (hLIF; $1000 \mathrm{u} \mathrm{ml}^{-1}$ ). For the second experiment pICMs were collected as above and cultured for 4 days in one of six treatments: control medium, human leukaemia inhibitory factor (hLIF; $\left.1000 \mathrm{u} \mathrm{ml}^{-1}\right)$, human interleukin $6\left(\mathrm{hLL}-6 ; 100 \mathrm{ng} \mathrm{ml}^{-1}\right)$, hIL-6+hIL-6 soluble receptor (hIL6+sR; $100 \mathrm{ng} \mathrm{ml}^{-1}+2.5 \mu \mathrm{g} \mathrm{ml}^{-1}$ ), human oncostatin $\mathrm{M}$ (hOSM; $100 \mathrm{ng} \mathrm{ml}^{-1}$ ), or rat ciliary neurotrophic factor (rCNTF; $100 \mathrm{ng} \mathrm{ml}^{-1}$ ). All cytokines were prepared in Dulbecco's Modified Eagles Medium:Hams F-10 (1:1)-based medium. Colonies were photographed daily for morphological analysis. pICMs were categorized into one of two types based on their morphological profile: type A, non-epithelial or type B, epithelial-like. Eight investigators evaluated pICM differentiation using standardized differentiation profiles. Each pICM series was graded on a scale of 1 (fully undifferentiated) to 5 (fully differentiated) for each time point. Differentiation was verified by alkaline phosphatase activity, cytokeratin staining and scanning electron microscopy. In Expt 1, neither hLIF nor culture medium delayed differentiation of the developing pICM. In Expt 2, differentiation was significantly lower on day 2 for rCNTF cultured pICMs versus hLIF cultured pICM $(2.07 \pm 0.15$ versus $2.70 \pm 0.16 ; P<0.05)$. Furthermore, addition of rCNTF gave the lowest overall mean differentiation score $(2.53 \pm 0.15)$. However, none of the cytokines significantly delayed differentiation over the control for the 4 day culture period. The grading system used was an effective tool for detecting treatment effects on differentiation of the developing pICM.

Since these heterologous cytokines were unable to inhibit differentiation significantly, it is unlikely that they will be beneficial in isolating pig ES cell lines under current conditions. Future work with homologous cytokines, protein half-lifes, and dose effects may prove more beneficial.

\section{Isolation and characterization of pig cytokines}

To determine whether homologous cytokines are more effective in inhibiting the differentiation of pig embryo-derived cells, we have isolated several of the pig haematopoietic cytokine genes. To date, we have isolated the genomic sequences for LIF, LIF receptor, ciliary neurotrophic factor (CNTF) and oncostatin M (OSM). 
Leukaemia inhibitory factor, LIF, is another haematopoietic cytokine that has been shown to promote the survival and proliferation of embryonic stem cells in culture (Smith et al., 1988; Williams et al., 1988; Wilson et al., 1992). Like CNTF, the heterologous protein is ineffective in isolating pig ES cell lines (Moore and Piedrahita, 1996; Moore and Piedrahita, 1997). As a result, we are attempting to express the pig LIF protein using a synthetic gene and test the effect of the homologous protein on the isolation of pig ES cells. In previous experiments with expression of the pLIF in mammalian cells (CHOs: Chinese hamster ovarian cells), we were able to detect only very low expression of pLIF by western blot analysis. As a result we decided to develop artificial genes that can be expressed in yeast using the method of Stemmer $e$ t al. (1995). One clone spanned the entire gene and had a minimal number of mismatches. These mistakes include: six single bp deletions, two of which lie within the linker and need not be repaired and five substitutions which are GCT/GCA: alanine, GCT/ACT: alanine to threonine, AGA/GGA: arginine to glycine, GCT/GGT: alanine to glycine, and AAG/GAG: lysine to glutamic acid. The first substitution does not change the amino acid that is incorporated and thus no repair is needed; however, the remaining mistakes change the amino acid and must be repaired before the protein can be expressed. Repairs will be made by performing in vitro site-directed mutagenesis using the Transformer Mutagenesis Kit (Clontech, Palo Alto, CA). Alternatively, PCR conditions can be optimized for a polymerase, such as Pfu, that has a higher fidelity and processivity than Taq for synthesizing the gene from the original twelve oligonucleotides. Once all repairs are complete and verified by sequencing, the synthetic gene will be cloned into pMLD8, the recombinant protein produced in Pichia pastoris, and its effectiveness on the isolation of pig ES cell lines tested in culture.

Ciliary neurotrophic factor (CNTF), a haematopoietic cytokine, can maintain mouse embryonic stem (ES) cells in culture (Conover et al., 1993). By interacting with its receptor and forming a hexamer that includes a gp130-LIFR heterodimer (Deserio et al., 1995), CNTF facilitates the activation of the gp130 signal transduction pathway (Ip et al., 1992; Stahl et al., 1993), which ultimately leads to maintenance of the undifferentiated, proliferating phenotype of the ES cell (Yoshida et al., 1994). As we have shown that heterologous CNTF does not positively contribute to the isolation of stable pig embryo-derived cell lines with characteristic ES cell morphology (Moore and Piedrahita, 1996), we have isolated and characterized the pig CNTF to determine the effects of the homologous protein on the inhibition of differentiation of early pig embryonic cells.

The pig CNTF gene, isolated from a phage genomic library, has been cloned, sequenced and assigned to chromosome 2 . Briefly, a 369 bp reverse transcription polymerase chain reaction (RT-PCR) probe synthesized from pig activated macrophage mRNA was used to identify positive phage clones. Of seven initial positives, one phage clone was purified through a tertiary screening and a $6 \mathrm{~kb}$ ApaI fragment identified by southern blotting as containing the whole gene was cloned into pBluescript (Stratagene Inc., La Jolla, CA) using shotgun cloning. Four subclones were constructed and all clones were sequenced using dye terminator automated cycle sequencing with the M13-20 and reverse primers; in addition, other primers were designed and synthesized as needed to sequence both strands of each clone entirely. The pig CNTF gene includes two exons separated by a 1258 bp intron (GenBank Accession no. U57644). The gene encodes a deduced polypeptide of 200 amino acids which showed $83 \%, 82 \%, 82 \%$ and $81 \%$ similarity to known sequences in the rabbit (Lin et al., 1989), rat (Stockli et al., 1989), human (Negro et al., 1991) and mouse (GenBank Accession no. U05342), respectively. Seven non-conservative amino acid changes were identified in the pig protein compared with other species which, if important in the function of the protein, may explain the inability of heterologous CNTF to activate the pig gp130 pathway. Comparison of the $5^{\prime}$ region of the pig CNTF and other mammalian cytokines indicates the presence of several conserved transcription factor binding motifs, suggesting their importance for controlling the specific expression of these proteins. In addition, CNTF has been localized to pig chromosomes by fluorescence in situ hybridization performed essentially as described by Niebergs ef al. (1993). Pig metaphase chromosomes were prepared from whole blood. All specific hybridization signals were localized on chromosome $2 p$, band 1.6, and arm length ratios calculated for 40 early metaphase chromosomes confirmed that the pig CNTF gene is located on chromosome $2 \mathrm{p} 1.6$. This assignment was further confirmed by aligning R-banded FISH labelled chromosomes to the standard idiogram and R-banded chromosome 2 of the pig (Committee for the Standand Karyotype of the Domestic Pig, 1988). 

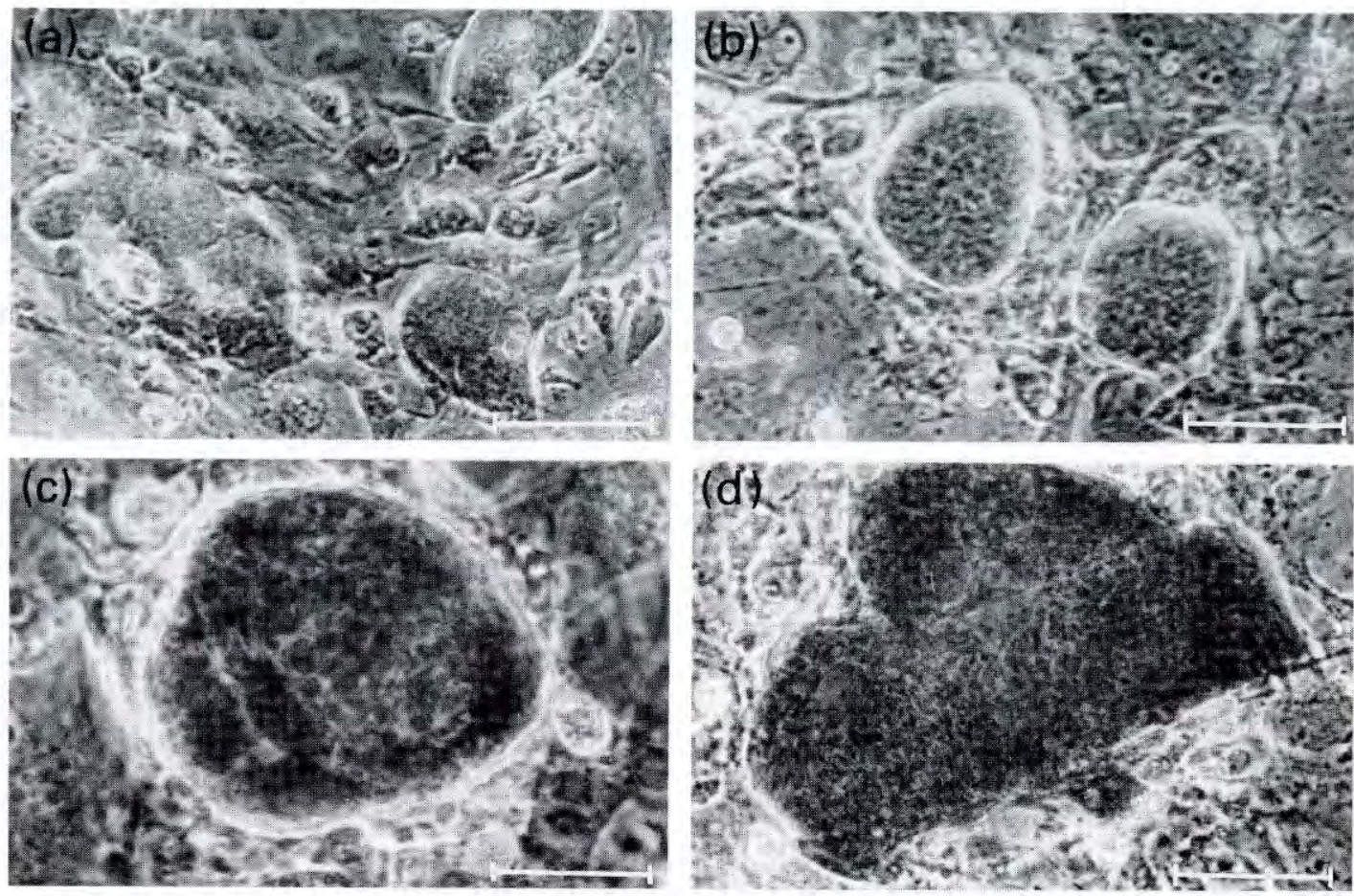

Fig. 1. Morphology and alkaline phosphatase (AP) activity of pig primordial germ cell-derived colonies after several passages. Cultured colonies were passaged at least twice before morphology and AP activity was recorded. (a) and (b) Pig embryonic stem (ES) cell-like cells (Scale bar represents (a) $50 \mu \mathrm{m}$ and (b) $25 \mu \mathrm{m}$ ); (c) and (d) pig AP-positive colonies (Scale bar represents $50 \mu \mathrm{m}$ ). Note in all cases the typical ES-like morphology with small cytoplasm, large nucleus and prominent nucleoli.

At present, we are preparing to introduce a synthetic version of pig CNTF in Pichia pastoris for expression and testing the bioactivity of the homologous protein compared with heterologous CNTF.

\section{Development and characterization of PGC-derived cell lines}

Isolation and maintenance of EG-like pig cells. Uteri of pigs at 25-27 days of pregnancy were collected at surgery, the fetuses dissected, and germ cells isolated as previously described by Labosky et al. (1994). Essentially, the genital ridge of the developing fetus was removed and incubated in

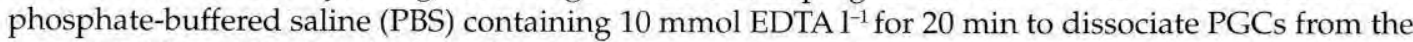
gonadal ridge. After incubation, the PGCs were gently released in culture media, centrifuged and resuspended in Dulbecco's modified Eagle's media:Ham's F10, supplemented with 0.01 mmol nonessential amino acids $1^{-1}, 2 \mathrm{mmol}$ glutamine $1^{-1}, 15 \%$ fetal bovine sera (selected batches, Summit Biotechnology), $0.1 \mathrm{mmol} 2$-mercapthoethanol $\mathrm{l}^{-1}$, soluble recombinant human stem cell factor at $40 \mathrm{ng} \mathrm{ml}^{-1}$, human basic fibroblast growth factor at $20 \mathrm{ng} \mathrm{ml}^{-1}$, and LIF at $20 \mathrm{ng} \mathrm{ml}^{-1}$ (PEG medium).

The cell suspension at a density of $10000 \mathrm{PGCs} \mathrm{ml}^{-1}$ was plated onto a feeder layer of STO cells prepared as described by Piedrahita et al. (1990). After 7-10 days of culture, colonies with ES-like morphology were passaged to fresh feeder layers for establishment of cell lines. Resulting colonies were passaged by trypsinization to fresh feeder layers at 6-9 day intervals. State of differentiation of isolated cell lines was determined by morphology and expression of alkaline phosphatase (AP), a marker of undifferentiated embryonic cells (Talbot et al., 1993). As seen in Fig. 1, colonies with typical 

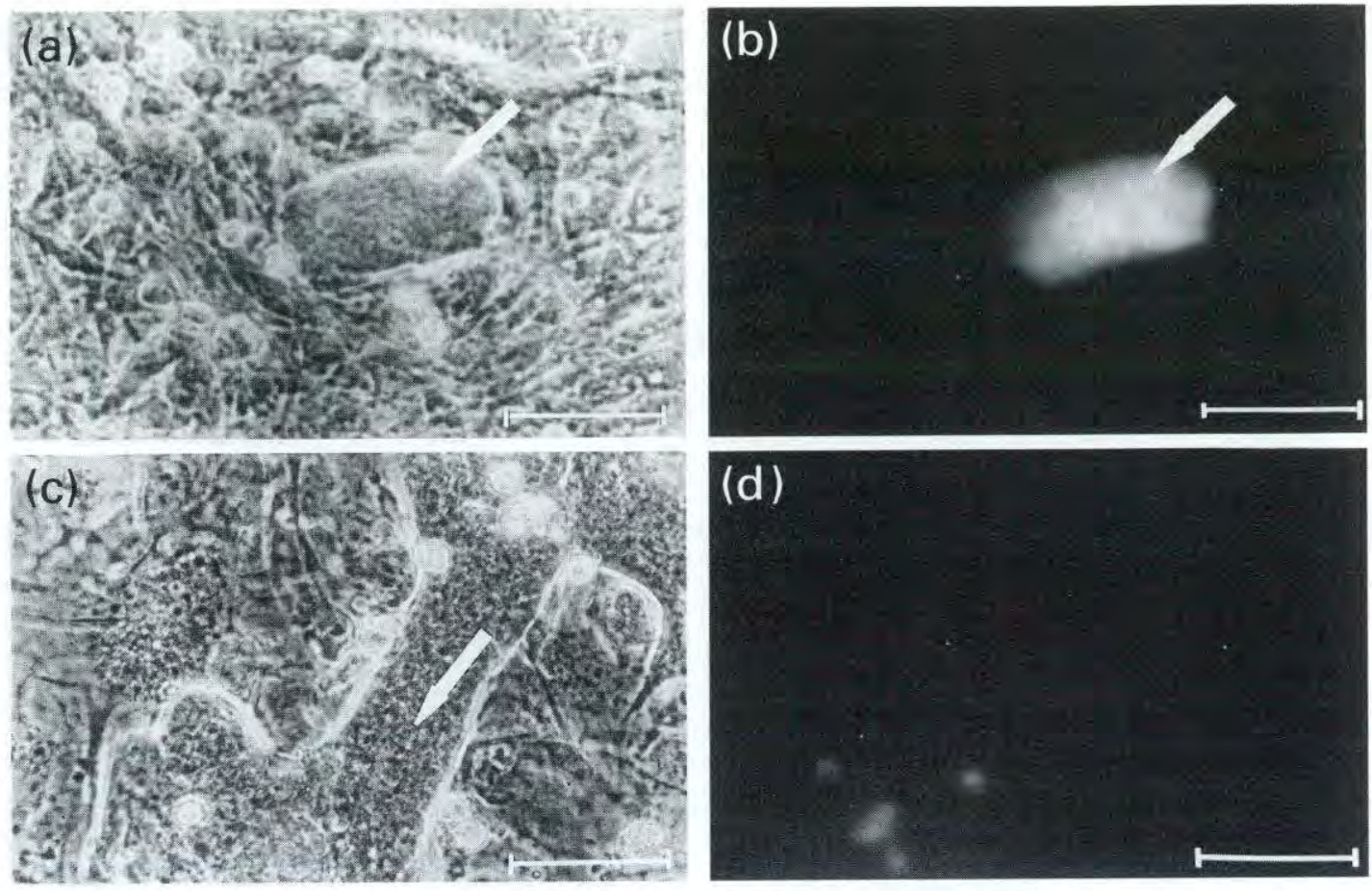

Fig. 2. Genetically transformed pig primordial germ cell (PGC)-derived colonies. PGCs were isolated and electroporated with a plasmid containing the green fluorescent protein (GFP) under the control of the cytomegalovirus promoter. Fourteen days after electroporation, colonies were examined under a fluorescent microscope. (a) Typical PGC-derived colony. The morphology of the colonies shown is similar to that seen in murine embryonic stem cell and embryonic germ cell colonies. (b) Same colony as (a) under fluorescent light. Note all cells are expressing GFP, indicating that the colony probably originated from a single transgenic cell. (c) Large non-transgenic PGC-derived colony in the same plate as (a) and (b). (d) Colony C under fluorescent light. Note the absence of any signal. Arrows indicate the location of the colony. Scale bar represents $50 \mu \mathrm{m}$.

ES and EG-like morphology were isolated from the PGCs. Moreover, we have been able to maintain these cell lines for up to 14 passages and 4 months while still retaining the alkaline phosphatase expression and the appropriate morphology.

Genetic transformation of pig PGCs. PGC-derived colonies were electroporated with a plasmid consisting of the 'humanized' green fluorescent protein (GFP) attached to the cytomegalovirus (CMV) promoter. After electroporation, cells were plated on fresh feeder layers and cultured for 8-12 days, and then observed under ultraviolet light (FITC filters) and fluorescent colonies identified (Fig. 2). Fluorescent colonies were picked and passed to fresh feeders for establishment of transgenic EG cell lines.

Ability of transgenic pig cultured PGCs to contribute to formation of chimaera. Transgenic PGCs isolated and transformed as described previously were identified, dissociated by trypsinization, and 10-15 cells injected into the blastocoel of the developing blastocyst or into the inner portion of compacted morulae. Injected embryos were transferred to synchronized recipients and fetuses collected at day 25 of pregnancy. For evaluation, fetuses were observed under fluorescent light for detection of the marker GFP. Unfortunately, owing to the high background fluorescence, the GFP could not be effectively used to identify chimaeric fetuses (Fig. 3). After visual inspection fetuses 

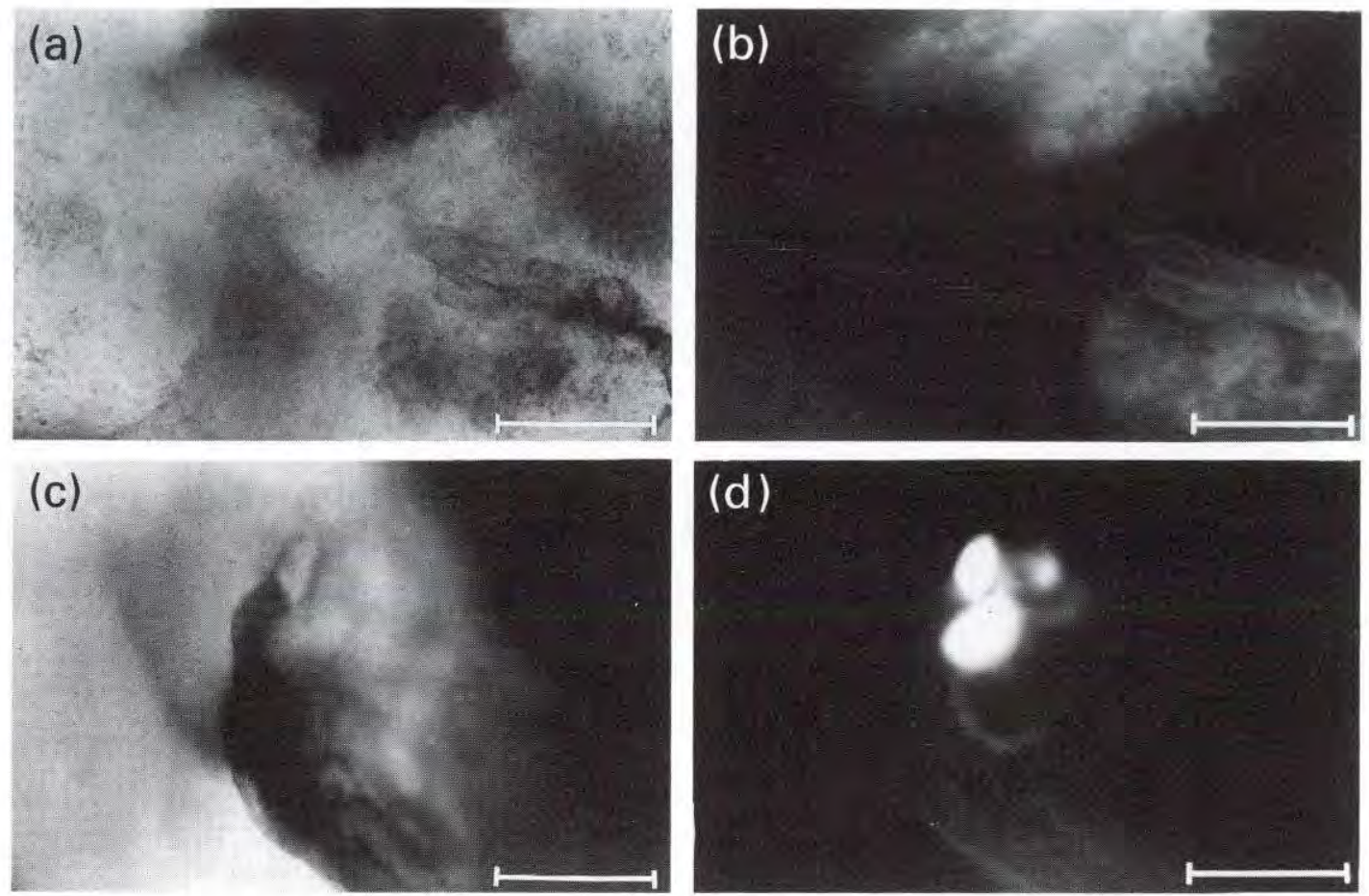

Fig. 3. Autofluorescence of fetal pig tissues. Analysis of non-transgenic 25-day-old pig fetuses under a fluorescent microscope equipped for fluorescein isothiocyanate excitation indicated that fetal tissues give a high autofluorescence signal. The intensity of the signal varied from a low, homogeneous signal (a, transmitted light and b, fluorescent light) to a strong signal associated with particular structures (c, light and d, fluorescent). Unfortunately, both types of autofluorescence makes use of GFP expression for the detection of transgenic chimaeric fetuses difficult. Scale bar represents $200 \mu \mathrm{m}$.

were minced and a fraction of the tissue used for DNA analysis, which consisted of detection of the GFP construct by genomic Southern blots. Of seven recipients receiving injected embryos, two were pregnant, and 14 normal fetuses and one resorbed fetus were obtained. Two of these were positive for the transgene by Southern blot analysis. The restriction enzymes selected can distinguish between a plasmid contaminant and DNA that is inserted in the genome (Fig. 4). For instance, the BstXI digest showed a hybridizing band of $8 \mathrm{~kb}$. As the initial construct is only $6.2 \mathrm{~kb}$, it is not possible to obtain such a band unless the construct is embedded in genomic DNA flanked by two BstXI sites. The HindIII digest cuts once inside the plasmid as well as in the flanking genomic DNA. From the pattern obtained, it is evident that both chimaeric animals had contributions from the same transformation event. As five colonies were isolated, trypsinized, and the cells used to inject into blastocysts, these results indicate that either only one of the five colonies had pluripotential abilities or that by chance, the two resulting chimaeras were derived from cells obtained from the same colony. To our knowledge this is the first report of transgenic cultured pig cells being able to take part in chimaera formation. The data presented above clearly indicate that transgenic pig EG cells can contribute to the development of a fetus when injected into a host blastocyst.

A disadvantage of the present technology in swine is the need for the generation of a germ-line chimaera and the required extra generation before a transgenic founder is produced. Although this is not a problem in mice which have short generation intervals, in pigs and other domestic species this extra generation can increase the costs per transgenic founder quite substantially. We are presently exploring the use of nuclear transfer technology (Liu et al., 1995; Ouhibi et al., 1996) as well 

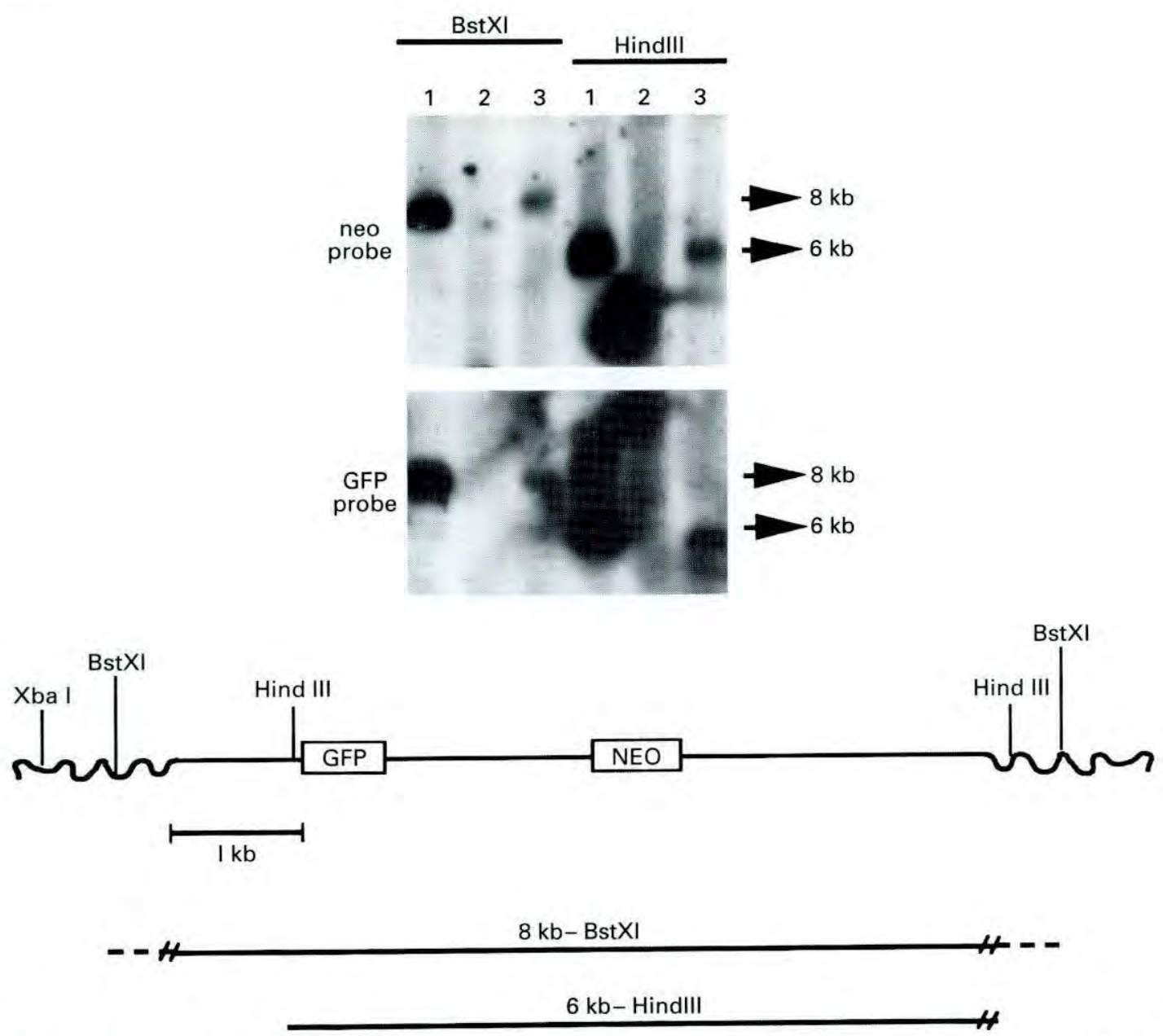

Fig. 4. Southern blot analysis of chimaeric fetal tissues. DNA samples obtained from pig fetuses previously identified as transgenic were digested with either Bst XI or HindIII, separated in $0.7 \%$ agarose and sequentially hybridized with a green fluorescent protein (GFP) probe and a neomycin (neo) probe. Lane (1) fetus number 9; lane (2) negative control fetus; lane (3) fetus number 10. The enzymes used for digestion were selected for their ability to differentiate between plasmid contamination and genomic incorporation as well as for determining the number of copies inserted. The $8 \mathrm{~kb}$ band obtained with the Bst XI digest unequivocally rules out the possibility of contamination as the initial plasmid was only $6.2 \mathrm{~kb}$ in length. Moreover, Bst XI does not cut within the introduced plasmid indicating that only one copy of the construct has incorporated into the genome. In addition, both digests corroborated the presence of both the GFP and the neogene in the inserted DNA, suggesting that no major DNA rearrangement occurred.

as the use of tetraploid embryos as hosts for chimaera formation (Nagy et al., 1990; Prather et al., 1996; Ueda et al., 1995) as potential methods reducing the time required for generation of a founder animal.

\section{Conclusion}

Recent advances in the isolation, culture and genetic manipulation of pig pluripotent stem cells (ES and EG) suggest that within the next few years it will be possible to introduce subtle genetic 
modification into the pig genome. Although biomedical applications of this technology, such as xenotransplantation and production of biopharmaceuticals in the milk, are obvious, the use of transgenic technologies in agricultural production systems is not as clear. This is due in part to the high costs of generating the transgenic animals but more importantly it is our lack of knowledge of how phenotypes of agricultural importance can be manipulated by modifying single genes. However, progress in the genetic manipulation of pigs combined with progress in the elucidation of the genetic control of phenotypes of agricultural importance will soon lead to the generation of transgenic pigs of use in agriculture.

\section{References}

Anderson GB, Choi SJ and BonDurant RH (1994) Survival of porcine inner cell masses in culture and after injection into blastocysts Theriogenology 42,212

Conover JC, IP NY, Poueymirou WT, Bates B, Goldfarb MP, DeChiara TM and Yancopoulos GD (1993) Ciliary neurotrophic factor maintains the pluripotentiality of embryonic stem cells Development 119 559-565

Deserio A, Graziani R, Laufer R, Ciliberto G and Paonessa G (1995) In vitro binding of ciliary neurotrophic factor to its receptors - evidence for the formation of an IL-6 type hexameric complex Joumal of Molecular Biology 254 795-800

Doetschman T, Williams P and Maeda N (1988) Establishment of hamster blastocyst-derived embryonic stem ES cells Developmental Biology 127 224-227

Doetschman T, Eistetter CH, Katz M, Schmidt $W$ and Kemler $R$ (1985) The in vitro development of blastocyst-derived embryonic stem cell lines: formation of visceral yolk sac, blood islands and myocardium Journal of Embryology and Experimentai Morphology 87 27-45

Evans MJ, Notarianni E, Laurie S and Moor RM (1990) Derivation and preliminary characterization of pluripotent cell lines from porcine and bovine blastocysts Theriogenology 33 125-128

Gerfen RW and Wheeler MB (1995) lsolation of embryonic celllines from porcine blastocysts Animal Biotechnology 6 1-14

Ip NY, Nye SH, Boulton TG, Davis S, Taga T, Li $Y$, Birren S], Yasukawa K, Kishimoto T, Anderson DJ, Stahl $\mathbf{N}$ and Yancopoulos GD (1992) CNTF and LIF act on neuronal cells via shared signaling pathways that involve the IL- 6 signal transducing receptor component gp130 Cell $691121-1132$

Koller B and Smithies O (1992) Altering genes in animals by gene targeting Annual Reviews of Immunology 10 705-730

Labosky PA, Barlow DP and Hogan BLM (1994) Mouse embryonic germ (EG) cell lines: transmission through the germline and differences in the methylation imprint of insulin-like growth factor 2 receptor $(I g f 2 r)$ gene compared with embryonic stem (ES) cell lines Development 120 3197-3204

Lin L-FH, Mismer D, Lile JD, Armes LG, Butler ET, III, Vannice JL and Collins F (1989) Purification, cloning, and expression of ciliary neurotrophic factor (CNTF) Science 246 1023-1025

Liu L, Moor RM, Laurie S and Notarianni E (1995) Nuclear remodelling and early development in cryopreserved, porcine primordial germ cells following nuclear transfer into in vitro-matured oocytes International Journal of Developmental Biology 39 871-880

Moore K and Piedrahita JA (1996) Effects of heterologous hematopoietic cytokines on in vitro differentiation of cultured porcine inner cell masses Molecular Reproduction and Development 45 139-144
Moore K and Piedrahita JA (1997) The effects of human leukemia inhibitory factor (hLif) and culture medium on in vitro differentiation of cultured porcine inner cell mass (plCM) In Vitro Cellular and Developmental Biology - Animal 33 62-71

Nagy A, Gocza E, Diaz EM, Prideaux VR, Ivanyi E, Markkula M and Rossant J (1990) Embryonic stem cells alone are able to support fetal development in the mouse Development 110 815-821

Negro A, Tolosano E, Skaper SD, Martini I, Callegaro L, Silengo L, Fiorini F and Altruda F (1991) Cloning and expression of human ciliary neurotrophic factor European Journal of Biochemistry 201 289-294

Niebergs HL, Gallagher DS, Georges M, Sargeant LS, Dietz AB and Womack JE (1993) Physical mapping of inhibin B-A in domestic cattle Mammalian Genome 4 328-332

Notarianni E, Laurie S, Moor RM and Evans MJ (1990) Maintenance and differentiation in culture of pluripotential embryonic cell lines from pig blastocysts Joumal of Reproduction and Fertility 41 51-56

Onishi A, Takeda K, Komatsu M, Akita T and Kojima T (1994) Production of chimeric pigs and the analysis of chimerism using mitochondrial deoxyribonucleic acid as a cell marker Biology of Reproduction 51 1069-1075

Ouhibi N, Fulka J, Jr, Kanka J and Moor RM (1996) Nuclear transplantation of ectodermal cells in pig oocytes: ultrastructure and radiography Molecular Reproduction and Development 44 533-539

Piedrahita JA, Anderson GB and BonDurant RH (1990) On the isolation of embryonic stem (ES) cells: comparative behavior of murine, porcine, and ovine embryos Theriogenology 34 879-901

Piedrahita JA, Zhang SH, Hagaman JR, Clark PM and Maeda N (1992) Generation of mice carrying a mutant apolipoprotein $\mathbf{E}$ gene inactivated by gene targeting in mouse embryonic stem cells Proceedings of the National Academy of Sciences, USA 89 4471-4475

Prather RS, Hoffman KE, Schoenbeck RA, Stumpf TT and Li J (1996) Characterization of DNA synthesis during the 2-cell stage and the production of tetraploid chimeric pig embryos Molecular Reproduction and Development $4538-42$

Pursel VG, Pinkert CA, Miller KF, Bolt DJ, Campbell RJ, Palmiter RD, Brinster RL, and Hammer RE (1989) Genetic engineering of livestock Science 244 1281-1288

Shim H, Gutiérrez-Adán A, Chen LR, Bon Durant RH, Behboodi E and Anderson GB (1997) Isolation of pluripotent stem cells from cultured porcine primordial germ cells Biology of Reproduction 57 1089-1095

Smith AG, Heath JK, Donaldson DD, Wong GG, Moreau J, Stahl M and Rogers D (1988) Inhibition of pluripotential embryonic 
stem cell diffenentiation by purified polypeptides Nature $336688-690$

Smithies $O$ (1991) Altering genes in humans and animals in Etiology of Human Disease at the DNA Level pp 221-230 Eds J Lindsten and U Petterson. Raven Press, New York

Stahl N, Davis S, Wong V, Taga T, Kishimoto T, Ip NY and Yancopoulos GD (1993) Cross-linking identifies leukemia inhibitory factor-binding protein as a CNTF receptor component Journal of Biological Chemistry 268 7628-7631

Stemmer WPC, Crameri A, Ha KD, Brennan TM and Heyneker HL (1995) Single-step assembly of a gene and entire plasmid from large numbers of oligodeoxyribonucleotides Gene 164 49-53

Stewart CL, Vanek M and Wagner EG (1985) Expression of foreign genes from retroviral vectors in mouse teratocarcinoma chimeras EMBO foumal 4 3701-3709

Stewart CL, Gadi I and Blatt H (1994) Stem cells from primordial germ cells can re-enter the germline Developmental Biology $161626-628$

Stice SL and Strelchenko NS (1995) Domestic animal embryonic stem cells: progress toward germ-line contribution. In Biotechnology's Role in the Genetic Improvement of Farm Animals p. $189 \mathrm{Eds}$ RH Miller, VG Pursel and H Norman. Beltsville Symposia in Agricultural Research, Beltsville, MD

Stockli KA, Lottspeich F, Sendtner M, Masiakowski P, Carroll 'P, Gotz R, Lindholm D and Thoenen H (1989) Molecular cloning, expression, and regional distribution of rat ciliary neurotrophic factor Nature 342 920-923
Strelchenko N (1996) Bovine pluripotent stem cells Theriogenology 45 131-140

Talbot NC, Rexroad CE, Pursel VG and Powell AM (1993a) Alkaline phosphatase staining of pig and sheep epiblast cells in culture Molecular Reproduction and Development 36 139-147

Ueda O, Jishage K, Kamada N, Uchida S and Suzuki H (1995) Production of mice entirely derived from embryonic stem (ES) cell with many passages by coculture of ES cells with cytochalasin B induced tetraploid embryos Experimental Animals 44 205-210

Wall RJ (1996) Transgenic livestock: progress and perspectives for the future Theriogenology 45 57-68

Wheeler MB (1994) Development and validation of swine embryonic stem cells - a review Reproduction Fertility and Development 6 563-568

Williams RL, Hilton DJ, Pease S, Willson TA, Stewart CL, Gearing DP, Wagner EF, Metcalf D, Nicola NA and Gough NM (1988) Myeloid leukaemia inhibitory factor maintains the developmental potential of embryonic stem cells Nature $336684-687$

Wilson TA, Metcalf D and Gough NM (1992) Cross-species comparison of the sequence of the leukemia inhibitory factor gene and its protein European Journal of Biochemistry 204 21-30

Yoshida K, Chambers I, Nichols ], Smith A, Mikiyoshi S, Yasukawa K, Shoyab M, Taga T and Kishimoto T (1994) Maintenance of the pluripotential phenotype of embryonic stem cells through dinect activation of gp130 signalling pathways Mechanisms of Development 45 163-171 